\title{
Penerapan model pembelajaran Snowball Throwing untuk meningkatkan hasil belajaran pada siswa kelas II SDN 01 Kalirejo Talun
}

\author{
Siti Nurasiyah \\ SD Negeri 01 Kalirejo Kec.Talun Kab.Pekalongan
}

\begin{tabular}{|c|c|}
\hline Article Info & ABSTRACT \\
\hline Article history: & \multirow{3}{*}{$\begin{array}{l}\text { The scope of elementary Indonesian subjects includes language and literary } \\
\text { skills, namely listening, speaking, reading and writing (Khasanah, 2015). } \\
\text { For this reason, the purpose of this research is the application of thelearning } \\
\text { model snowball throwing to improve learning outcomes for second grade } \\
\text { students at SDN 01 Kalirejo Talun. This type of research is Classroom } \\
\text { Action Research (CAR). The subjects in this study were 19th graders of } \\
\text { SDN } 01 \text { Kalirejo Talun. Data collection methods used in this study are } \\
\text { tests, observations, documentation and interviews. The data analysis } \\
\text { technique used is descriptive both qualitatively and quantitatively. For the } \\
\text { success criteria in this study, the indicator of success in this study is } \\
\text { individual learning completeness if the proportion of students' correct } \\
\text { answers is more than the predetermined KKM and for classical learning } \\
\text { completeness if at least } 85 \% \text { of students score above the predetermined } \\
\text { KKM, which is } 75 \text {. The results of In this study, cycle } 1 \text { shows that the } \\
\text { number of students who have reached the predetermined KKM is } 14 \\
\text { students with a percentage of } 78.95 \% \text {. Meanwhile, the results of cycle } 2 \\
\text { show that the number of students who have reached the predetermined } \\
\text { KKM is } 17 \text { students with a percentage of } 89.57 \% \text {. }\end{array}$} \\
\hline $\begin{array}{l}\text { Received : } 30 \text { Agustus } 2021 \\
\text { Revised : } 22 \text { September } 2021 \\
\text { Accepted : } 28 \text { September } 2021\end{array}$ & \\
\hline $\begin{array}{l}\text { Keywords: } \\
\text { individual learning; language and } \\
\text { literary; reading and writing; } \\
\text { students }\end{array}$ & \\
\hline & \\
\hline
\end{tabular}

How to Cite: Nurasiyah, S. (2021). Penerapan Model Pembelajaran Snowball Throwing untuk meningkatkan hasil belajaran pada siswa kelas II. Action Research Journal, 1(1): 148-152.

\section{PENDAHULUAN}

Bahasa Indonesia merupakan salah satu mata pelajaran yang sangat penting sehingga diajarkan mulai dari sekolah dasar. Pentingnya mata perlajaran bahasa Indonesia terdapat dalam UU Sisdiknas tahun 2003 pada Bab III pasal 4 ayat 4 tentang Prinsip-prinsip Penyelenggaraan Pendidikan disebutkan bahwa pendidikan diselenggarakan dengan mengembangkan budaya membaca, menulis dan berhitung bagi segenap warga masyarakat. Zuleha (2012) menyatakan kompetensi mata pelajaran bahasa Indonesia di SD merupakan kualifikasi minimal dari siswa yaitu terkait keterampilan berbahasa, dan sikap positif terhadap bahasa dan sastra Indonesia. Khasanah (2015) menyatakan ruang lingkup mata pelajaran bahasa Indonesia SD meliputi kemampuan berbahasa dan bersastra yaitu mendengarkan, berbicara, membaca dan menulis.

Mengingat begitu pentinyanya bahasa Indonesia, maka diperlukan upaya agar mata pelajaran tersebut mudah dipahami oleh siswa dengan cara meningkatkan hasil belajar terhadap mata pelajaran tersebut. Salah satu upaya yang dapat dilakukan adalah penggunaan model pembelajaran yang seusai dan inovatif. Trianto (2010) menyatakan model pembelajaran merupakan suatu perencanaan atau pola yang digunakan sebagai pedoman dalam merencanakan pembelajaran di kelas atau pembelajaran tutorial. Asyafah (2019) menyatakan model pembelajaran yang efektif sangat membantu dalam proses pembelajaran sehingga tujuan pembelajaran lebih mudah tercapai, dapat memberikan informasi yang berguna bagi siswa dalam proses pembelajarannya serta variasi model pembelajaran dapat memberikan gairah 
belajar, menghindari rasa bosan, dan akan berimplikasi pada minat serta motivasi siswa dalam mengikuti proses pembelajaran.

Salah satu model pembelajaran yang dapat digunakan pada siswa SD kelas II adalah model pembelajaran Snowball Throwing. Huda (2014) menyatakan model pembelajaran snowball throwing yaitu model yang dilakukan dengan melempar segumpalan kertas untuk menunjuk siswa yang diharuskan menjawab soal dari guru. Akhiriyah (2011) menyatakan model pembelajaran snowball throwing dapat menciptakan suasana menyenangkan dalam proses pembelajaran dan membangkitkan motivasi siswa. Hamdayama (2014: 158) menyatakan model snowball throwing membagi siswa dalam beberapa kelompok, masing-masing anggota kelompok membuat sebuah pertanyaan pada selembar kertas dan membentuk sebuah bola, kemudian bola tersebut dilempar ke siswa yang lain selama durasi waktu yang ditentukan, yang selanjutnya masing-masing siswa menjawab pertanyaan dari bola yang diperoleh. Namun, berdasarkan data awal hasil belajar, nilai siswa kelas II SDN 01 Kalirejo Talun masih rendah. Hal tersebut dinyatakan dalam tabel 1 sebagai berikut.

Tabel 1. Nilai Awal Hasil Belajar Siswa Kelas II SDN 01 Kalirejo Talun

\begin{tabular}{cccc}
\hline Nilai & Jumlah Siswa & Persentase & Kriteria Ketuntasan \\
\hline$\geq 75$ & 9 & $47,37 \%$ & Tuntas \\
$<75$ & 10 & $52,63 \%$ & Belum tuntas \\
Jumlah & 19 & $100,00 \%$ & \\
\hline
\end{tabular}

Berdasarkan Tabel 1, terlihat bahwa terdapat 10 siswa yang belum memenuhi ketuntasan individu yaitu 75 dengan persentase 52,63\%. Sementara terdapat 9 siswa yang telah memenuhi ketuntasan individu dengan persentase $47,27 \%$. Berdasarkan permasalahan di atas, tujuan dari penelitian ini adalah penerapan model pembelajaran snowball throwing untuk meningkatkan hasil belajar pada siswa kelas II SDN 01 Kalirejo Talun.

\section{METODE}

Jenis penelitian ini adalah Penelitian Tindakan Kelas (PTK). Hopkins dalam Muslich (2009) menyatakan PTK merupakan kajian yang dilakukan oleh peneliti untuk meningkatkan kemantapan rasional dari tindakan-tindakannya dalam melaksanakan tugas dan memperdalam pemahaman terhadap kondisi dalam praktik pembelajaran. Arikunto (2010) menjelaskan PTK merupakan suatu pencermatan terhadap kegiatan belajar berupa sebuah tindakan, yang sengaja dimunculkan dan terjadi dalam sebuah kelas secara bersama. Subjek dalam penelitian ini adalah siswa kelas II SDN 01 Kalirejo Talun yang berjumlah 19 orang. Metode pengumpulan data .yang digunakan dalam penelitian ini yaitu tes, observasi, dokumentasi dan wawancara. Teknik analisis data yang digunakan adalah deskriptif baik secara kualitatif maupun kuantitatif. Untuk tes hasil belajar siswa, dihitung jumlah skor dari masing-masing siswa dengan rumus rata-rata sebagai berikut.

$$
\begin{aligned}
& \text { Mean }=\frac{\sum x}{N} \\
& \text { Keterangan } \\
& \text { Mean = nilai rata-rata siswa } \\
& \sum x \quad=\text { jumlah nilai seluruh siswa } \\
& N \quad=\text { jumlah siswa }
\end{aligned}
$$

Untuk menghitung persentase ketuntasan klasikal kelas dapat ditentukan menggunakan rumus sebagai berikut.

$$
\text { Persentase }=\frac{\text { jumlah siswa yang tuntas atau belum tuntas }}{\text { jumlah seluruh siswa }}
$$

Untuk kriteria keberhasilan dalam penelitian ini, Indikator keberhasilan pada penelitian ini adalah ketuntasan belajar individu jika proporsi jawaban siswa yang benar lebih dari KKM yang telah ditetapkan dan untuk ketuntasan belajar klasikal jika minimal $85 \%$ siswa mendapat nilai diatas KKM yang telah ditetapkan yaitu 75 . 
Terdapat berbagai desain PTK yang dikemukakan oleh para ahli. Untuk penelitian ini, desain penelitian ini menggunakan model spiral dari kemmis dan Mc. Taggart yang dinyatakan pada Gambar 1 sebagai berikut.

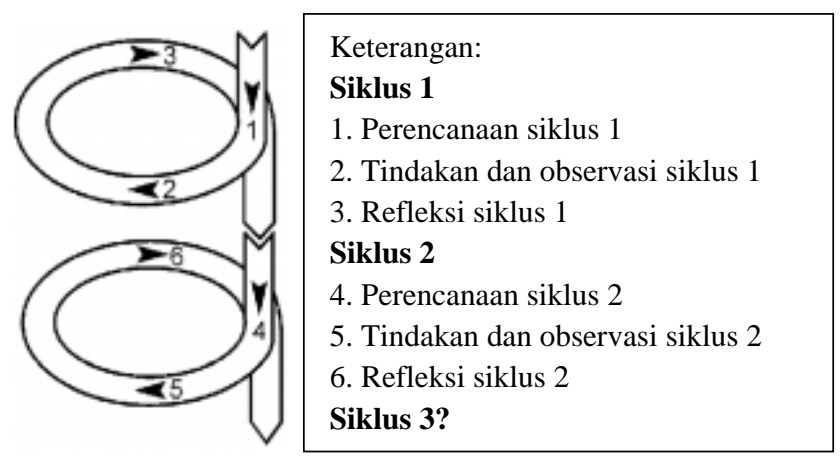

Gambar 1. Siklus PTK Menurut Kemmis dan Mc Taggart

Penjelasan dari Gambar 1, dapat dijelaskan sebagai berikut.

\section{Perencanaan}

Mempersiapkan materi pelajaran dalam pelaksanaan tindakan, mempersiapkan RPP yang akan digunakan dalam penelitian dengan mengacu pada sintaks model pembelajaran snowball throwing, mempersiapkan instrumen berupa tes, lembar pengamatan.

2. Tindakan dan observasi

Pada tahap ini, melaksanakan proses pembelajaran pada siswa kelas II SDN 01 kalirejo Talun menggunakan model pembelajaran snowball throwing sesuai dengan rencana yang telah dibuat. Tahap obervasi dilakukan selama proses pembelajaran menggunakan model snowball throwing dengan mencatat dan merekam kegiatan yang dilakukan oleh siswa.

3. Refleksi

Pada tahap ini, peneliti melakukan analisis terhadap data yang telah diperoleh kemudian menentukan apakah telah mencapai indikator keberhasilan yang telah ditetapkan. Hasil dari analisis tersebut dijadikan acuan apakah diperlukan atau tidak dalam menjalankan siklus 2 .

\section{HASIL DAN PEMBAHASAN}

Penelitian dilaksanakan sebelum adanya pandemi Covid-19 yaitu pada semester gasal 2019/2020. Nilai hasil belajar mata pelajaran bahasa Indonesia pada siswa kelas II SDN 01 Kalirejo Talun didapatkan dari siklus 1 dan siklus 2. Hasil belajar siswa terlihat pada Tabel 2.

Tabel 2. Hasil belajar Bahasa Indonesia pada siswa kelas II SDN 01 Kalirejo Talun siklus 1

\begin{tabular}{cccl}
\hline Nilai & Jumlah Siswa & Persentase & Kriteria ketuntasan \\
\hline$\geq 75$ & 14 & $78,95 \%$ & Tuntas \\
$<75$ & 5 & $21,05 \%$ & Belum tuntas \\
\hline Jumlah & 19 & $100,00 \%$ & \\
\hline
\end{tabular}

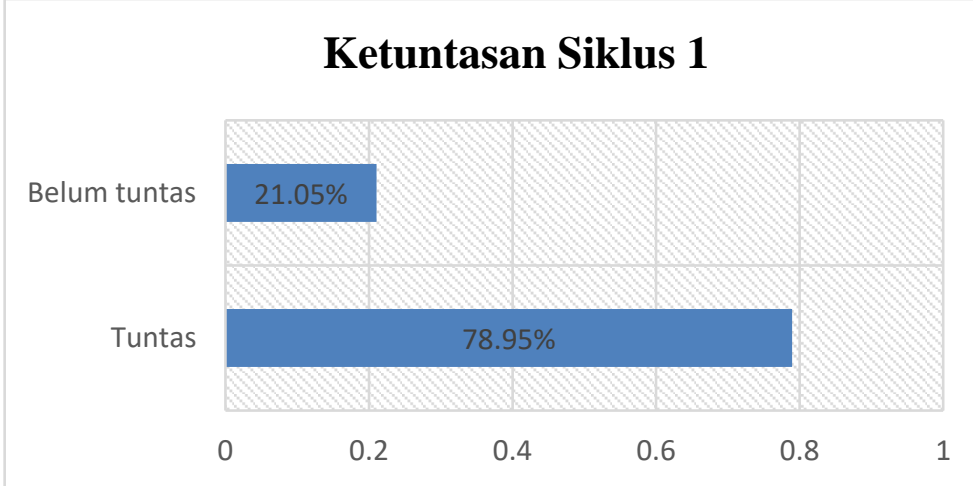

Gambar 2. Ketuntasan Belajar Siswa Siklus 1 
Berdasarkan Tabel 2 serta Gambar 2 yang menunjukkan hasil dari siklus 1, terlihat bahwa jumlah siswa yang telah mencapai KKM yang telah ditetapkan berjumlah 14 siswa dengan persentase sebesar $78,95 \%$. Sementara untuk siswa yang belum mencapai KKM yang telah ditetapkan berjumlah 5 siswa dengan persentase sebesar 21,05\%. Karena belum memenuhi indikator keberhasilan yang telah ditetapkan, maka peneliti melanjutkan ke siklus 2. Data hasil siklus 2 dapat dilihat pada Tabel 3 dan Gambar 3.

Tabel 3. Hasil belajar Bahasa Indonesia pada siswa Kelas II SDN 01 Kalirejo Talun siklus 2

\begin{tabular}{cccc}
\hline Nilai & Jumlah Siswa & Persentase & Kriteria ketuntasan \\
\hline$\geq 75$ & 17 & $89,47 \%$ & Tuntas \\
$<75$ & 2 & $10,53 \%$ & Belum tuntas \\
\hline Jumlah & 19 & $100,00 \%$ & \\
\hline
\end{tabular}

\section{Ketuntasan Siklus 2}

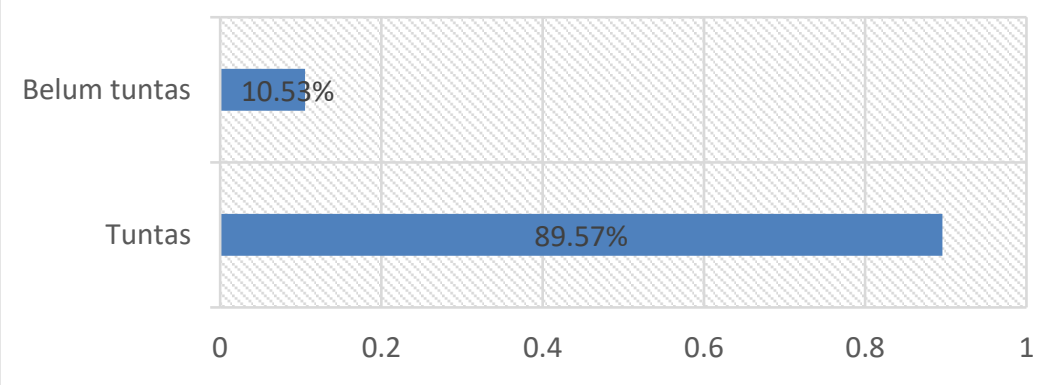

Gambar 3. Ketuntasan belajar siswa siklus 2

Berdasarkan Tabel 3 dan Gambar 3 yang menunjukkan hasil dari siklus 2, terlihat bahwa jumlah siswa yang telah mencapai KKM yang telah ditetapkan berjumlah 17 siswa dengan persentase sebesar $89,57 \%$. Sementara untuk siswa yang belum mencapai KKM yang telah ditetapkan berjumlah 2 siswa dengan persentase sebesar 10,53\%. Karena telah memenuhi indikator keberhasilan yang telah ditetapkan, maka peneliti tidak perlu melanjutkan ke siklus selanjutnya.

Dari hasil di atas, terjadi peningkatan yang signifikan dari siklus 1 ke siklus 2 . Hal ini dikarenakan ketika siswa melakukan proses pembelajaran menggunakan model snowball throwing, siswa merasa sangat antusias dan senang dalam proses tersebu, sehingga tujuan pembelajaran lebih mudah tercapai. Sebagaimana pernyataan Akhiriyah (2011) bahwa model pembelajaran snowball throwing dapat menciptakan suasana menyenangkan dalam proses pembelajaran dan membangkitkan motivasi siswa. Huda (2014) menyatakan model pembelajaran snowball throwing yaitu model yang dilakukan dengan melempar segumpalan kertas untuk menunjuk siswa yang diharuskan menjawab soal dari guru.

Dari hasil pengamatan juga terlihat bahwa dengan menggunakan model pembelajaran snowball throwing, siswa juga lebih berani dalam mengemukakan jawaban jika terpilih. Karena aturan dari model tersebut sudah disampaikan oleh guru dari awal, kemudian untuk siswa yang terpilih harus mengemukakan jawabannya. Hal tersebut sesuai dengan pendapat Uno (2011) bahwa model pembelajaran snowball throwing merupakan kegiatan pembelajaran yang memberikan kesempatan siswa untuk berpendapat, kemudian dipadukan secara berpasangan, berkelompok, dan yang terakhir secara klasikal untuk mendapatkan pandangan dari seluruh siswa atau siswa di kelas. Hal senada juga dikemukakan oleh Komalasari (2010) bahwa pembelajaran snowball throwing adalah model pembelajaran yang menggali potensi kepemimpinan siswa dalam kelompok dan keterampilan membuat- menjawab pertanyaan yang dipadukan melalui suatu permainan imajinatif membentuk dan melempar bola salju.

Penelitian dilaksanakan sebelum adanya pandemi Covid-19 yaitu pada semester gasal 2019/2020. Nilai hasil belajar mata pelajaran bahasa Indonesia pada siswa kelas II SDN 01 Kalirejo Talun didapatkan dari siklus 1 dan siklus 2.pada siklus I persentase hasil belajar siswa 
mata pelajaran bahasa Indoneisa dengan model pembelajaran Snowball Throwing dengan persentase $78,95 \%$ pada siklus II mengalami kenaikan menjadi $89,47 \%$.

\section{PENUTUP}

Berdasarkan hasil penelitian dan pembahasan di atas, maka dapat disimpulkan bahwa penerapan model pembelajaran snowball throwing dapat meningkatkan hasil belajaran pada siswa kelas II SDN 01 Kalirejo Talun. Hal ini terlihat dari dari indikator keberhasilan pada siklus 1 sebesar $78,95 \%$ dan meningkat pada siklus 2 sebesar $89,57 \%$. Saran yang dapat diberikan oleh peneliti adalah agar guru dapat lebih menggunakan model pembelajaran yang inovatif seperti model snowball throwing agar siswa lebih tertarik, lebih antusias, menyenangkan dalam proses pembelajaran, berani mengemukakan pendapat dan dapat meningkatkan hasil belajar siswa.

\section{DAFTAR PUSTAKA}

Akhiriyah, D. W. (2011). Penerapan Model Pembelajaran Snowball Throwing untuk Meningkatkan Kualitas Pembelajaran IPS pada Siswa Kelas V SDN Kalibanteng Kidul 01 Kota Semarang, Jurnal Kependidikan Dasar, Vol. 1, No. 2.

Arikunto, S. (2011). Penelitian Tindakan Kelas. Jakarta: PT Rineka Cipt

Asyafah, A. (2019). Menimbang Model Pembelajaran (Kajian Teoretis-Kritis atas Model Pembelajaran dalam Pendidikan Islam). Tarbawy Indonesian Journal of Islamic Education. Vol 6 No. 1. E-ISSN. 2599-2481.

Depdiknas. (2003). Undang-Undang RI No.20 tahun 2003 tentang Sistem Pendidikan Nasional. Jakarta: Depdiknas.

Hamdayama, J. (2014). Model dan Metode Pembelajran Kreatif dan Berkarakter. Jakarta: Ghalia Indonesia.

Huda, M. (2014). Model-Model Pengajaran dan Pembelajaran (Isu-isu Metodis dan Paradigmatis). Yogyakarta: Pustaka Pelajar

Khasanah, T. O. (2015). Pengembangan Bahan Ajar Teks Percakapan pada Mata Pelajaran Bahasa Indonesia dengan Media Gambar Di Kelas V SD N Pokoh I Ngemplak Sleman DIY Tahun Pelajaran 2014/2015. Skripsi (tidak dipublikasikan). Program studi pendidikan guu sekolah dasar Universitas PGRI Yogyakarta.

Komalasari, K. (2010). Pembelajaran Kontekstual: Konsep dan Aplikasi. Bandung: Rafika Aditama.

Masnur, M. (2009). Melaksanakan PTK (Penelitian Tindakan Kelas) itu Mudah. Jakarta: PT Bumi Aksara

Trianto. (2010). Model Pembelajaran Terpadu Konsep, Strategi, Dan Implementasinya Dalam Kurikulum Tingkat Satuan Pendidikan (KTSP). Jakarta: Bumi Aksara

Uno, H. (2011). Teori Motivasi dan Pengukurannya. Jakarta: PT Bumi AksaraBandung PT Remaja Rosdaka Karya

Zulela M.S. (2012). Pembelajaran bahasa IMasnur Muslich, Masnur. 2009. Melaksanakan PTK (Penelitian Tindakan Kelas) itu Mudah. Jakarta: PT Bumi Aksara 